\title{
High-precision analysis of $\mathrm{SF}_{6}$ at ambient level
}

\author{
J. S. Lim ${ }^{1}$, D. M. Moon ${ }^{1}$, J. S. Kim ${ }^{1}$, W.-T. Yun ${ }^{2}$, and J. Lee ${ }^{1}$ \\ ${ }^{1}$ Korea Research Institute of Standards and Science (KRISS), Division of Metrology for Quality Life, P.O. Box 102, Yuseong, \\ Daejeon, South Korea \\ ${ }^{2}$ Climate Policy Division, Climate Science Bureau, Korea Meteorological Administration, 61 16-gil, Yeouidaebang-ro, \\ Dongjak-gu, Seoul 156-720, South Korea
}

Correspondence to: J. Lee (leejs@kriss.re.kr)

Received: 6 September 2012 - Published in Atmos. Meas. Tech. Discuss.: 29 October 2012

Revised: 7 June 2013 - Accepted: 8 June 2013 - Published: 5 September 2013

\begin{abstract}
This work reports on the development of a technique for the precise analysis of ambient $\mathrm{SF}_{6}$. This technique, which involves a gas chromatograph/electron capture detector (GC-ECD) coupled with an Activated Alumina-F1 (AAF1) column, performed well in the measurements, particularly in terms of accuracy, which complies with the World Meteorological Organization (WMO)-recommended compatibility of $0.02 \mathrm{ppt}$. Compared to the Porapak $\mathrm{Q}$ technique, we observed a sharper peak shape for the $\mathrm{SF}_{6}$ stream, which substantiates the improvement in the analytical precision. The traceability to the WMO scale was tested by calibrating the GC-ECD/AA-F1 analyser using five $\mathrm{SF}_{6}$ standards provided by the WMO/Global Atmosphere Watch (GAW) Central Calibration Laboratory (CCL) for $\mathrm{SF}_{6}$ (NOAA, United States of America). After calibration by various methods, the GC-ECD/AA-F1 accurately estimated the mole fraction of $\mathrm{SF}_{6}$ in the working standard prepared by the World Calibration Centre for $\mathrm{SF}_{6}$ operated by the Korea Meteorological Administration (KMA)/Korea Research Institute of Standards and Science (KRISS). Among the calibration methods, the two-point calibration method emerged to be the most economical procedure in terms of the data quality and measurement time. It was found that the KRISS scale of $\mathrm{SF}_{6} / \mathrm{N}_{2}$ was biased by $0.13 \mathrm{ppt}$ when compared to the WMO scale of $\mathrm{SF}_{6} /$ air; this bias is probably due to a different matrix.
\end{abstract}

\section{Introduction}

Greenhouse gases (GHGs) in the atmosphere, which absorb and emit solar thermal energy, are known to be the prime cause of global warming. The Kyoto Protocol, which entered into force in 2005, binds a number of countries with an obligation to reduce the human-activity-induced emissions of four greenhouse gases $-\mathrm{CO}_{2}, \mathrm{CH}_{4}, \mathrm{~N}_{2} \mathrm{O}$, and $\mathrm{SF}_{6}-$ and two groups of halocarbon gases, which include hydrofluorocarbons and perfluorocarbons. Consequently, most industrialised nations have devoted tremendous effort in reducing and even restricting the anthropogenic emissions of GHGs. In order to standardise the accuracy and compatibility of the measurements, the Bureau International des Poids et Mesures (BIPM; International Bureau of Weights and Measures) and the World Meteorological Organization (WMO) have carried out several international comparisons of the greenhouse gas standards (van der Veen et al., 2007; Wessel et al., 2008; Dlugokencky et al., 2005; Lee et al., 2011). WMO and BIPM signed a memorandum of understanding (MOU) to ensure better collaboration and authorisation of non-metrology institutions supporting the Quality Assurance system within the GAW Programme to take part in the BIPM coordinated key comparisons.

Among the greenhouse gases mentioned, $\mathrm{SF}_{6}$, despite its low global mean mole fraction $(5-10 \mathrm{ppt})$, has attracted a lot of attention due to its long lifetime of 600-3200 yr in the troposphere. Its high global warming potential - 22800 times greater than that of $\mathrm{CO}_{2}-$ makes it one of the most potent GHGs. The global mean of $\mathrm{SF}_{6}$ was measured as $7.5 \mathrm{ppt}$ in 2012 (HATS database, 2013) and its growth rate is evaluated to be up to $\sim 0.28 \mathrm{ppt} \mathrm{yr}^{-1}$ (GAW Report No. 186, 2009; Rigby et al., 2010; Hall et al., 2011).

Naturally, the observation of $\mathrm{SF}_{6}$ has become a vigorous activity under the GAW (Global Atmosphere Watch) Programme, which is supported by 80 countries and up to 400 observatory sites worldwide. Among those, 37 sites for $\mathrm{SF}_{6}$ 
observation are located mostly on the European and American continents, according to the Global Atmosphere Watch Station Information System (GAWSIS). The Korea Meteorological Administration (KMA), with technical cooperation from the Korea Research Institute of Standards and Science (KRISS), recently agreed to host the World Calibration Centre (WCC) for $\mathrm{SF}_{6}$ in order to contribute to the programs of the WMO and GAW on the global observations of $\mathrm{SF}_{6}$. At present, the establishment of a high-quality measurement system with reliable compatibility between the observation sites is regarded as a task of highest priority, taking into consideration the complications associated with the analytical results generated by a gas chromatography-electron capture detector (GC-ECD) system, which is the typical tool for the analysis of $\mathrm{SF}_{6}$.

In this study, we describe the analysis of $\mathrm{SF}_{6}$ using a GC-ECD analyser coupled with an Activated Alumina-F1 (AA-F1) column; we also compared the performance of our method with that of the Porapak Q (PP-Q) technique. The working standards, prepared as dry air standards in aluminium cylinders, were analysed using the GC-ECD/AA-F1 calibrated against the $\mathrm{WMO} \mathrm{SF}_{6}$ scale. Using these results, the $\mathrm{SF}_{6}$ mole fraction of the working standards with associated analytical uncertainty was assigned by various calibration methods. In addition, a comparison between the WMO and KRISS standards is discussed.

\section{Experimental methods}

\subsection{Analyser preparation and measurement capability}

Gas chromatography (GC) was used for the high-precision analysis of $\mathrm{SF}_{6}$ gas mixtures in this study. Analytes were fed into the GC at a constant flow rate, which was regulated by a well-calibrated mass flow controller (M3030V, Line Tech., Korea). A P-5 (5\% $\mathrm{CH}_{4}$ in $\mathrm{Ar}, 45 \mathrm{psi}$ ) gas was used to carry the analytes through the gas lines and an Activated AluminaF1 column (4 m, ID $2.0 \mathrm{~mm}$, OD 1/8", 80-100 mesh, Restek) (Fig. 1). A clean and constant condition of the gas lines and the column was maintained to ensure good repeatability of measurement results. The Activated Alumina-F1 (AAF1) column was baked at $180^{\circ} \mathrm{C}$ between measurement cycles for $5 \mathrm{~min}$ to wash out potential contaminants, which may cause long-term reduction of the response and separating power. The well-known "backflush" method used in the presence of pre-column, which prevents the late-eluting compounds from reaching the main column (Hall et al., 2011), is a more gentle treatment method than the baking method, but it was not tried in this study. Gas lines configured to have a low dead volume were continuously rinsed. Using the regulator without a gauge, we expected to reduce the unwanted contribution of gases moored in the dead volume. Furthermore, restrictors at the ends of vent lines kept the pressure constant along the sample injection line, column, and

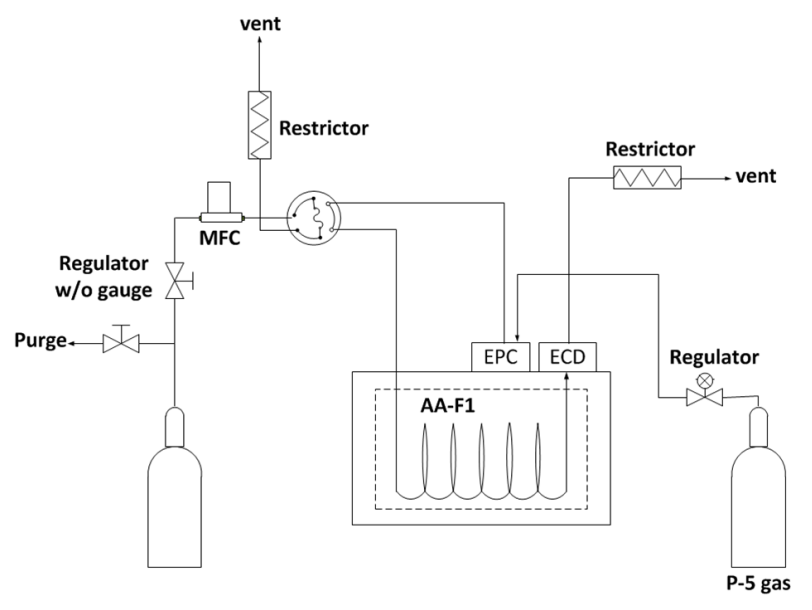

Fig. 1. Schematic diagram of the experimental setup. Using the regulator without a gauge, the unwanted contribution of gases moored in the dead volume was expected to be reduced. Two restrictors virtually isolated the instrument from variation in the ambient conditions of the lab and, therefore, lead to reasonable repeatability of the measurement results. EPC and ECD stand for the electronic pressure controller and electron capture detector, respectively. A series of measurements were performed while manually switching the left cylinder betweem sample and standard.

detector, regardless of ambient pressure (Fig. 1). This configuration helped to get a reasonably steady response factor. Chromatograms were then recorded, using the signal intensity of an electron capture detector ( $\mu \mathrm{ECD}$, Agilent $6890 \mathrm{~N})$, as a function of the retention time of analytes in the column.

In order to show the resolving power of the GC-ECD/AAF1, chromatograms taken by Activated Alumina-F1 and Porapak Q (4 m, ID $2.0 \mathrm{~mm}$, OD 1/8", 80-100 mesh, Restek) were compared. Both Porapak Q (PP-Q) and activated alumina-F1 (AA-F1) columns can separate $\mathrm{SF}_{6}$ from the background matrix under identical measurement conditions ( $4 \mathrm{~m}$ of column length, oven temperature of $35^{\circ} \mathrm{C}$, detector temperature of $380^{\circ} \mathrm{C}$, and carrier gas flow of $28 \mathrm{~mL} \mathrm{~min}^{-1}$ ). As depicted in Fig. 2, it is clearly shown that tighter elution of $\mathrm{SF}_{6}$ stream strongly imply excellent ability of the AA-F1 for $\mathrm{SF}_{6}$ analysis, compare to the PP-Q. As an additional benefit of using AA-F1, potential signal interference between $\mathrm{N}_{2} \mathrm{O}$ (260-360 ppb at ambient level) and $\mathrm{SF}_{6}(5-10 \mathrm{ppt}$ at ambient level), which appears later and gains lower sensitivity with PP-Q, can be avoided by virtue of the longer separation. It should be noted that a combination of PP-Q and molecular sieve 5A (Hall et al., 2011) also results in similar separation and analytical precision of $\mathrm{SF}_{6}$, but this combination requires two column ovens operating at different temperatures; this disadvantage increases maintenance effort.

In order to correct the instrument drift, we performed a series of measurements while switching analytes from sample to reference (Table 1). These consecutive measurements yielded a converging ratio value as follows: 

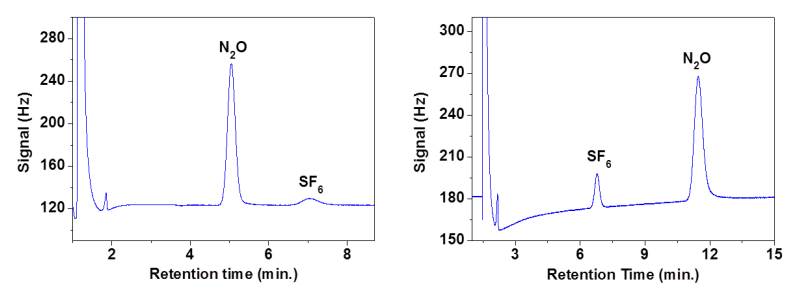

$<$ Analytical condition>

Column : Porapak-Q, $4 \mathrm{~m}$

$(2 \mathrm{~m} \times 2$ ea, ID $2.0 \mathrm{~mm}$, OD 1/8", 80-100 mesh)

Temp. of oven, ECD: $35{ }^{\circ} \mathrm{C}, 380{ }^{\circ} \mathrm{C}$

Carrier gas : $\mathrm{P} 5,45 \mathrm{psi}(28 \mathrm{ml} / \mathrm{min})$

Sample Flow, Volume: $100 \mathrm{ml} / \mathrm{min}, 2 \mathrm{ml}$

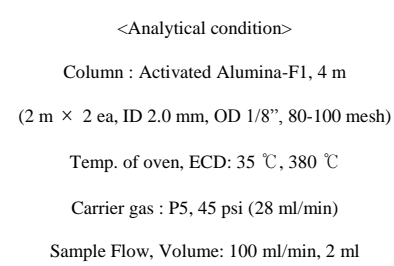

Fig. 2. Chromatograms taken using the GC-ECD coupled with two different types of columns installed in the GC.

$S_{i} \cdot 2 /\left(R_{i}+R_{i+1}\right)$,

where $S_{i}$ is the peak area of the $i$ th sample and $R_{i}$ is that of the $i$ th reference. Through this method, a short-term drift of the instrument $(<0.3 \%$ relative) was considerably reduced with the help of the term in denominator, $\left(R_{i}+R_{i+1}\right) / 2$, which tracks the variation of the detection sensitivity. The standard deviation $(1 \sigma)$ of five ratios was $0.19 \%$, which satisfies the compatibility goal recommended by the WMO for the measurement of $\mathrm{SF}_{6}( \pm 0.02 \mathrm{ppt})$. It is worthwhile to mention here that the $\mathrm{N}_{2} \mathrm{O}$ at ambient levels can be measured to within $\sim 0.5 \mathrm{ppb}$ of an analytical uncertainty by means of the AA-F1 technique. For testing the ECD response, the peak areas corresponding to $\mathrm{SF}_{6}$ were determined using five NOAA gas cylinders with mole fractions of 3.946, 5.920, $7.972,9.595$, and 11.887 ppt (Fig. 3, Table 2). Eventually, the response values obtained from the calibrated analyser gets to be traceable to the WMO scale.

\subsection{Preparation of working standard}

Traditionally, $\mathrm{SF}_{6}$ mole fraction scales have been provided by three laboratories, at the National Oceanic and Atmospheric Administration (NOAA), the University of Heidelberg, and the Scripps Institution of Oceanography (SIO). The compatibility between these three scales is generally known to be good (GAW Report No. 186, 2009). Nevertheless, because of the necessity for reliable comparison among $\mathrm{SF}_{6}$ observation stations, the requirement for a unified scale has arisen. Accordingly, WMO/GAW has adopted the NOAA $\mathrm{SF}_{6}$ scale as the WMO reference scale, which will be maintained by NOAA in their role as the Central Calibration Laboratory (CCL). In addition, CCL as a central facility supplies well-calibrated air to GAW analytic laboratories as needed for conducting inter-comparisons in collaboration with WCC
Table 1. Repeated measurement of reference and sample in order to compensate for instrumental drift between measurement cycles; every area data point is a result of three successive analyses.

\begin{tabular}{lrrrr}
\hline $\begin{array}{l}\text { Number of } \\
\text { measurements* }\end{array}$ & $\begin{array}{r}\text { Peak } \\
\text { area }\end{array}$ & $\begin{array}{r}\text { Ratio Value } \\
S_{i} \cdot 2 /\left(R_{i}+R_{i+1}\right)\end{array}$ & $\begin{array}{r}\text { Deviation } \\
{[\%]}\end{array}$ & $\begin{array}{r}\text { Instrumental } \\
\text { drift [\%] }\end{array}$ \\
\hline R1 & 473.04 & & & \\
S1 & 541.89 & 1.1454 & 0.00 & \\
R2 & 473.17 & & & +0.03 \\
S2 & 541.80 & 1.1439 & -0.13 & \\
R3 & 474.10 & & & -0.20 \\
S3 & 541.31 & 1.1427 & -0.23 & -0.20 \\
R4 & 473.29 & & & \\
S4 & 541.72 & 1.1465 & 0.10 & -0.33 \\
R5 & 471.70 & & & \\
S5 & 541.99 & 1.1483 & 0.26 & +0.12 \\
R6 & 472.27 & & & \\
\hline Average & & 1.1454 & & \\
Standard deviation & 0.0022 & & \\
\hline
\end{tabular}

* $R_{i}$ stands for $i$ th reference measurements and $S_{i}$ does $i$ th sample measurement.

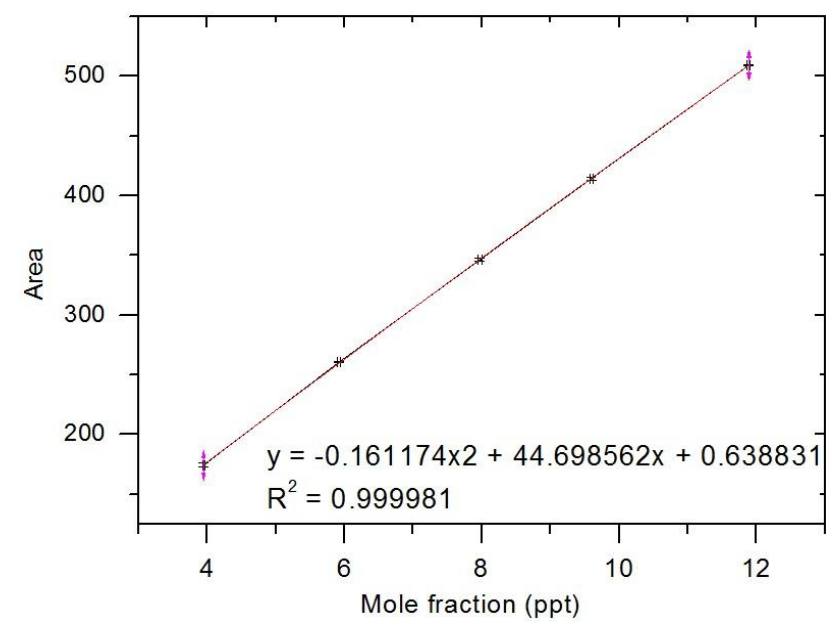

Fig. 3. Peak area plot as a function of the assigned mole fraction of the WMO standards. The response curve was approximated by a least square fit of a second-order polynomial with an agreement of $R^{2}=0.99981$. Residuals are listed in Table 2 .

or RCC (Regional Calibration Center; GAW Report No. 172, 2009).

Dry air for sampling was captured into a $29.5 \mathrm{~L}$ aluminium Luxfer cylinder (UK, CC315007) that was evacuated to less than $10^{-3} \mathrm{mbar}$ for a few hours. Then, an oil-free air compressor (SA-3E series, RIX Industries) pumped air into this prepared cylinder. To remove the air moisture during the sampling process, a chemical trap filled with granulated magnesium perchlorate $\left(\mathrm{Mg}\left(\mathrm{ClO}_{4}\right)_{2}\right)$ was inserted into the air flow line. After sampling, the $\mathrm{SF}_{6}$ mole fraction was assigned by the GC/ECD analyser calibrated by the WMO standards (Fig. 4). 
Table 2. Analytical results of $\mathrm{SF}_{6}$ standard gases from the NOAA.

\begin{tabular}{|c|c|c|c|c|c|c|c|}
\hline $\begin{array}{l}\text { Calibration } \\
\text { scale }\end{array}$ & Cyl. No. & $\begin{array}{r}C_{\text {assigned }}^{\mathrm{a}} \\
\quad[\mathrm{ppt}]\end{array}$ & $\begin{array}{r}\text { Standard } \\
\text { deviation }^{\mathrm{a}} \\
{[\mathrm{ppt}]}\end{array}$ & Peak area & $\begin{array}{r}C_{\text {calculated }}^{\mathrm{b}} \\
{[\mathrm{ppt}]}\end{array}$ & $\begin{array}{l}\text { Differ } \\
\text { [ppt] }\end{array}$ & {$[\%]$} \\
\hline \multirow[t]{5}{*}{ WMO scale } & FB03441 & 3.946 & 0.015 & 174.12 & 3.937 & -0.009 & -0.23 \\
\hline & FB03443 & 5.920 & 0.017 & 260.51 & 5.941 & +0.021 & +0.36 \\
\hline & FB03444 & 7.972 & 0.023 & 346.38 & 7.964 & -0.008 & -0.10 \\
\hline & FB03447 & 9.595 & 0.018 & 414.28 & 9.585 & -0.010 & -0.10 \\
\hline & FB03450 & 11.887 & 0.020 & 509.43 & 11.893 & +0.006 & +0.05 \\
\hline
\end{tabular}

${ }^{\mathrm{a}} C_{\text {assigned }}$ and standard deviation is a preassigned value of NOAA standards. ${ }^{\mathrm{b}} C_{\text {calculated }}$ is a value estimated from the approximated response curve at the corresponding peak area. The function of the approximated curve is given in Fig. 3 . ${ }^{c}$ Difference $=C_{\text {calculated }}-C_{\text {assigned }}$.

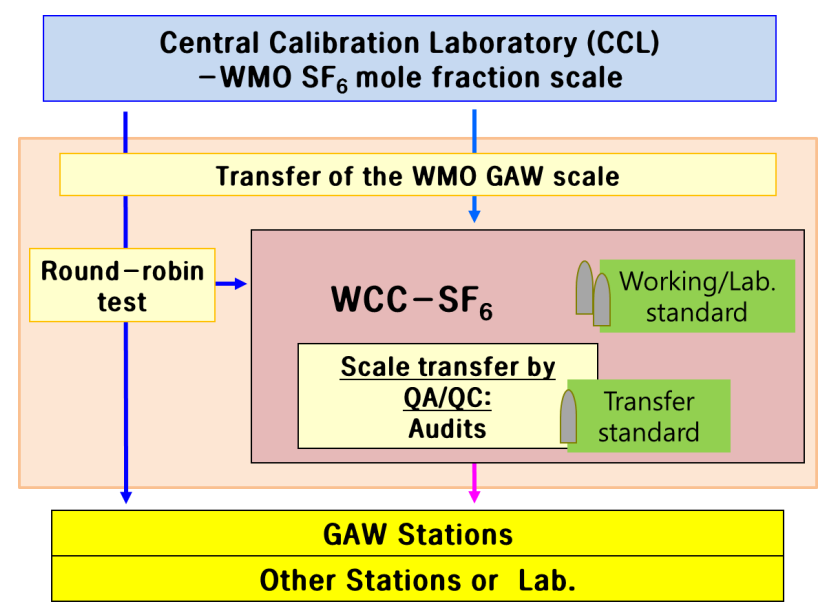

Fig. 4. Traceability chain of $\mathrm{SF}_{6}$ from the CCL and GAW stations.

\section{Results}

\subsection{High-precision analysis for $\mathrm{SF}_{6}$}

Figure 5 shows two overlaid chromatograms: one was a chromatogram of the working standard (CC315007, in air), and the other was that of the WMO cylinder (FB03443, in air). Due to the identity of the used matrix, a close proximity of the overall shapes was observed. Based on the assumption that the straight calibration curve is ensured in the molefraction interval of interest, a routine calibration such as single- and two-point methods can be carried out. In the single-point calibration, the mole fraction of the working standard was determined using following equation:

$C_{\text {unknown }}=\left(\frac{R_{\text {unknown }}}{R_{\text {ref }}}\right) \cdot\left(C_{\text {ref }}\right)$,

where $C$ is the mole fraction of $\mathrm{SF}_{6}, R$ is the response area, and the subscripts stand for the references and the unknown sample. Using the standard FB03443 (5.92 ppt) for one point calibration the working standard, which was assigned a value of $7.52 \mathrm{ppt}$ from the multi-point calibration,

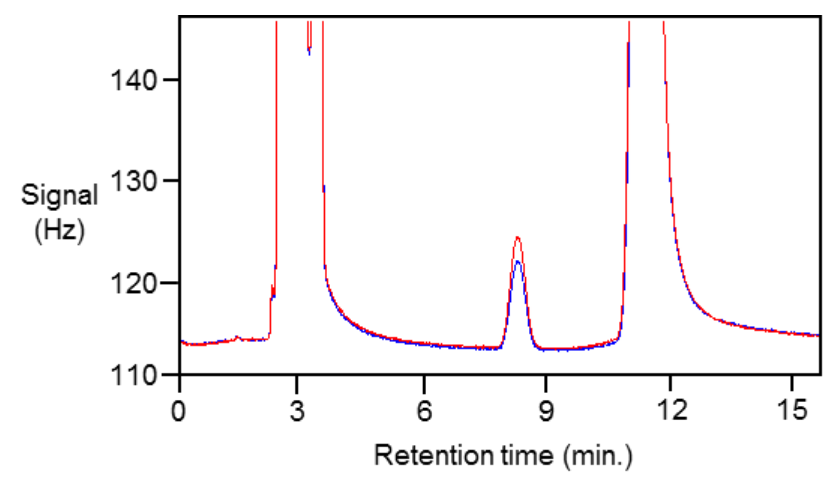

Fig. 5. Chromatogram of a working standard (CC315007, red) overlaid on one of the five WMO cylinders (FB03443, blue)

was found to be $7.45 \mathrm{ppt}(0.07 \mathrm{ppt}$ lower). While using the FB03444 (7.97 ppt) for one point calibration, the working standard was found to be $7.54 \mathrm{ppt}$ (that is only $0.02 \mathrm{ppt}$ higher). It is therefore suggested that the linearity of ECD response cannot be guaranteed outside the range of at least $0.45 \mathrm{ppt}$. The associated uncertainty was then determined using the following equation:

$$
\begin{aligned}
& u\left(C_{\text {unknown }}\right)=\left(\frac{R_{\text {unknown }}}{R_{\text {ref }}}\right) \cdot\left(C_{\text {ref }}\right) . \\
& \sqrt{\left(\frac{u\left(R_{\text {unknown }}\right)}{R_{\text {unknown }}}\right)^{2}+\left(\frac{u\left(R_{\text {ref }}\right)}{R_{\text {ref }}}\right)^{2}+\left(\frac{u\left(C_{\text {ref }}\right)}{C_{\text {ref }}}\right)^{2}},
\end{aligned}
$$

where $u\left(R_{i}\right)$ is the measurement uncertainty considering the drift correction, and $u\left(C_{\text {ref }}\right)$ is the standard deviation of the NOAA standard. The uncertainties were found to be $0.03 \mathrm{ppt}$ for both FB03443 and FB03444 references.

To improve a degree of accuracy, the two-point calibration method was then considered. With the nearest bracketing by FB03443 and FB03444, the $\mathrm{SF}_{6}$ mole fraction of the working standard was determined by the following equation:

$$
C_{\text {unknown }}=\left(\frac{R_{\text {unknown }}-R_{\text {ref1 }}}{R_{\text {ref2 }}-R_{\text {ref1 }}}\right)\left(C_{\text {ref2 }}-C_{\text {ref1 }}\right)+C_{\text {ref1 }} \text {. }
$$


Table 3. Calculated result of $\mathrm{SF}_{6}$ in the working standard $\mathrm{CC} 315007$ depending on the calibration methods that are referred to the WMO scale. Unit is ppt.

\begin{tabular}{lllllll}
\hline $\begin{array}{l}\text { Calibration } \\
\text { methods }\end{array}$ & Multi-point & \multicolumn{2}{c}{ Three-point } & Two-point & \multicolumn{2}{c}{ One-point } \\
\hline $\begin{array}{l}\text { WMO scales } \\
\text { FB03443 }\end{array}$ & FB03441 & FB03441 & FB03443 & FB03443 & FB03443 & FB03444 \\
$\begin{array}{l}\text { FB03444 } \\
\text { FB03447 }\end{array}$ & FB03444 & FB03444 & FB03444 & & & \\
FB03450 & & FB03447 & & & & \\
\hline $\begin{array}{l}\text { Calculated } \\
\text { value }\end{array}$ & 7.520 & 7.516 & 7.524 & 7.524 & 7.446 & 7.541 \\
\hline $\begin{array}{l}\text { Difference from } \\
\text { multi-point } \\
\text { calibration method }\end{array}$ & & -0.004 & +0.004 & +0.004 & -0.074 & +0.021 \\
\hline
\end{tabular}

Table 4. Total uncertainty budget of the working standard (CC315007).

\begin{tabular}{lrlrl}
\hline \multicolumn{2}{c}{ Uncertainty factor } & \multicolumn{2}{l}{ Standard uncertainty } & Note \\
\hline$R_{\text {unknown }}$ & 327.65 & $u\left(R_{\text {unknown }}\right)$ & 0.61 & for 3 repeats \\
$R_{\text {ref1 }}$ & 260.51 & $u\left(R_{\text {ref1 }}\right)$ & 0.51 & for 3 repeats \\
$R_{\text {ref2 }}$ & 346.38 & $u\left(R_{\text {ref } 2}\right)$ & 0.65 & for 3 repeats \\
$C_{\text {ref1 }}$ & $5.920 \mathrm{ppt}$ & $u\left(C_{\text {ref1 }}\right)$ & 0.017 & Preassigned \\
$C_{\text {ref2 }}$ & $7.972 \mathrm{ppt}$ & $u\left(C_{\text {ref } 2)}\right)$ & 0.023 & Preassigned \\
$C_{\text {unknown }}$ & $7.524 \mathrm{ppt}$ & $u\left(C_{\text {unknown }}\right)$ & 0.037 & Two-point calibration \\
\hline
\end{tabular}

Further, the associated uncertainty was propagated as follows:

$$
\begin{aligned}
& u\left(C_{\text {unknown }}\right)^{2}=
\end{aligned}
$$

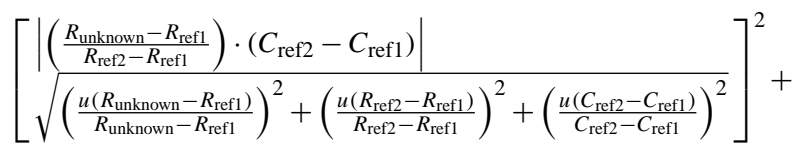

$$
\begin{aligned}
& u\left(C_{\text {ref } 1}\right)^{2}
\end{aligned}
$$

where $u\left(R_{i}-R_{j}\right)$ is equal to $\sqrt{u\left(R_{i}\right)^{2}+u\left(R_{j}\right)^{2}}$. Final assignment of the mole fraction of the working standard is $7.52 \pm 0.04 \mathrm{ppt}$. The elements of the uncertainty budget are tabulated in Table 4. To approximately compensate the quadratic response of the detector over atmospheric levels of $\mathrm{SF}_{6}$, a bracketing calibration with the WMO scale can be applied.

Values calculated using the various calibration methods are compared in Table 3. Slight deviations among calibration methods can be considered as analytical imperfections. Nevertheless, the calculated mole fractions were still within the values of the recommended compatibility goal. A significant difference was seen only when the single-point method was employed. Thus, we suggest the two-point calibration method as a higher priority method for the certification of a working standard, considering the measurement time and reliability of the data.

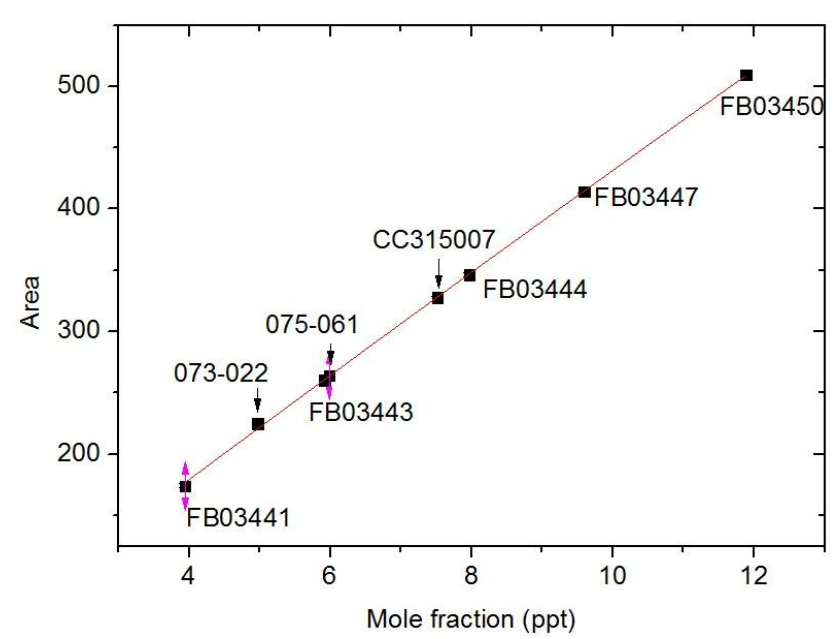

Fig. 6. Responses of working standard (CC315007, in air) prepared at $\mathrm{WCC}-S F_{6}$ and KRISS gravimetric standards (073-022 and 075061 , both in nitrogen). KRISS standards are biased by $0.13 \mathrm{ppt}$ from WMO scales due to the matrix effect.

\subsection{Comparison between the WMO standards and the KRISS standards}

Comparison analysis between the three selected WMO standards and the two KRISS standards was carried out. KRISS standards were prepared by gravimetrical method (ISO 6142, 2001). Since the matrix was pure nitrogen, counterchecking to pick up traces of $\mathrm{SF}_{6}$ in nitrogen $(99.999 \%$, Doek-yang Energen, Korea) became a very critical process to obtain an accurate value of the $\mathrm{SF}_{6}$ mole fraction. The GC/ECD chromatogram (Fig. 7) shows an $\mathrm{SF}_{6}$ trace in a high-purity $\mathrm{N}_{2}$ cylinder, suggesting the importance of impurity analysis. Here it should be noted that gas lines were rinsed clean using different $\mathrm{N}_{2}$ cylinders between cycles of impurity analysis. Even though the amount of $\mathrm{SF}_{6}$ impurity was found to be less than $0.01 \mathrm{ppt}$, it is negligible from the point of 
Table 5. Measurement results of the comparison between the WMO and KRISS standards.

\begin{tabular}{llrrrrrr}
\hline $\begin{array}{l}\text { Calibration } \\
\text { scale }\end{array}$ & Cyl. No. & $\begin{array}{r}C_{\text {Assigned }} \\
\text { [ppt] }\end{array}$ & $\begin{array}{r}\text { Standard } \\
\text { deviation } \\
\text { [ppt] }\end{array}$ & $\begin{array}{r}\text { Peak } \\
\text { area }\end{array}$ & $\begin{array}{r}C_{\text {calculated }} \\
\text { [ppt] }\end{array}$ & $\begin{array}{c}\text { Difference* } \\
\text { [ppt] }\end{array}$ & {$[\%]$} \\
\hline WMO standards & FB03443 & 5.920 & 0.017 & 221.92 & 5.917 & -0.003 & -0.04 \\
& FB03444 & 7.972 & 0.023 & 295.93 & 7.978 & +0.006 & +0.07 \\
& FB03447 & 9.595 & 0.018 & 353.90 & 9.592 & -0.003 & -0.03 \\
\hline KRISS standards & ME5591 & 7.237 & 0.02 & 272.81 & 7.334 & +0.097 & +1.34 \\
& ME5499 & 8.999 & 0.02 & 337.23 & 9.128 & +0.129 & +1.43 \\
\hline
\end{tabular}

$*$ Difference $=C_{\text {calculated }}-C_{\text {assigned }}$.

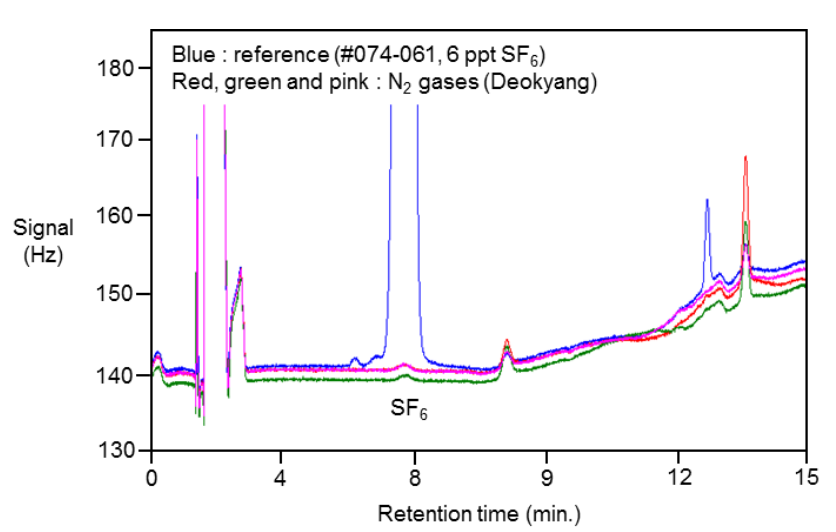

Fig. 7. Chromatograms of trace $\mathrm{SF}_{6}$ in pure nitrogen (red, green, and pink) and KRISS $\mathrm{SF}_{6}$ standard (blue, 6 ppt in nitrogen).

view of excessive nitrogen, a 6-ppt $\mathrm{SF}_{6}$ mixture should be biased by $0.17 \%$. Another potential deviation between the $\mathrm{SF}_{6}$ mole fractions of the WMO standards and the KRISS standards can be caused by the different matrices used. Supposing that the different matrices induced an alteration of the gas flow rate at the thermal mass flow controller (MFC), different amounts of gas mixture might possibly be loaded in the sample loop of constant volume (Min et al., 2009). Considering similar molecular weight of nitrogen to air and higher flow rate $\left(100 \mathrm{~mL} \mathrm{~min}^{-1}\right)$ compared to the sample size $(2 \mathrm{~mL})$, this effect seems to be very minor. Rather, the presence of oxygen in the WMO standards can temporarily affect the ECD response regardless of arrival time at the detector. Nevertheless, the KRISS standards listed in Table 5 seem to be in reasonable agreement with the WMO standards (agreement within $0.13 \mathrm{ppt}$ ). We believe that air-balanced standards should reduce a degree of the deviation between the WMO and the KRISS scales. In the near future, for equivalent comparison with the WMO scales, we will carry out a gravimetric preparation of an $\mathrm{SF}_{6}$ standard with synthetic air comprising $0.78 \mathrm{~mol} / \mathrm{mol} \mathrm{N}_{2}, 0.21 \mathrm{~mol} / \mathrm{mol} \mathrm{O}_{2}$, and $0.01 \mathrm{~mol} / \mathrm{mol} \mathrm{Ar}$.

\section{Summary and conclusion}

A high-precision analysis of $\mathrm{SF}_{6}$ at ambient conditions is presented. Instead of using the typical Porapak $\mathrm{Q}$ column, an Activated Alumina F1 column was coupled with a GC-ECD for measurement of $\mathrm{SF}_{6}$. The accuracy of the measurement was improved by (1) optimised analytical conditions for the complete isolation of the $\mathrm{SF}_{6}$ measurement, (2) meticulous care taken in the elimination of potential contaminants built up in the column and (3) correction of the short-term drift of the instrument. Namely, the optimized analytical conditions represented by the narrow $\mathrm{SF}_{6}$ peak supported the precision tests attempted in this study. With the help of the short-term drift correction, the measurement uncertainty was restricted to less than $0.02 \mathrm{ppt}$, which satisfies the compatibility goal recommended by $\mathrm{WMO}$ for $\mathrm{SF}_{6}$. Various calibration methods for calculating the $\mathrm{SF}_{6}$ mole fraction of the working standard prepared at $\mathrm{WCC}_{-} \mathrm{SF}_{6}$, operated by KMA/KRISS, were presented. The two-point calibration method emerged to be the most efficient in terms of measurement time and reliability of the data. It was found that the matrix effect caused a difference of $0.13 \mathrm{ppt}$ in the mole fraction between the two scales prepared by KRISS and NOAA. We believe that mimicking the air composition for the main balance improves the gap between the KRISS and the WMO scales. The study of the gravimetric generation of an $\mathrm{SF}_{6}$ standard mixture in artificial air will be reported in the near future.

Acknowledgements. This work was supported by the Korea Research Council of Fundamental Science and Technology (KRCF) under the National Agenda Project of Development of Measurement Technology for solving climate change (NAP-08-2) and by the Korea Meteorological Administration (KMA) under the project of Research on quality improvement of WMO World Calibration Center for Greenhouse gas monitoring (12138168100). The authors wish to thank their KRISS and KMA colleagues for continued cooperation and useful discussions.

Edited by: O. Tarasova 


\section{References}

Dlugokencky, E. J., Myers, R. C., Lang, P. M., Masarie, K. A., Crotwell, A. M., Thoning, K. W., Hall, B. D., Elkins, J. W., and Steele, L. P.: Conversion of NOAA atmospheric dry air $\mathrm{CH}_{4}$ mole fractions to a gravimetrically prepared standard scale, J. Geophys. Res., 110, D18306, doi:10.1029/2005JD006035, 2005.

GAW Report No. 172: Global Atmosphere Watch (GAW) Strategic Plan: 2008-2015, WMO, 2009.

GAW Report No. 186: 14th WMO/IAEA Meeting of Exerts on Carbon Dioxide, Other Greenhouse Gases and Related Tracers Measurement Techniques, WMO, 2009.

Hall, B. D., Dutton, G. S., Mondeel, D. J., Nance, J. D., Rigby, M., Butler, J. H., Moore, F. L., Hurst, D. F., and Elkins, J. W.: Improving measurements of $\mathrm{SF}_{6}$ for the study of atmospheric transport and emissions, Atmos. Meas. Tech., 4, 2441-2451, doi:10.5194/amt-4-2441-2011, 2011.

HATS (The Halocarbons and other Atmospheric Trace Species) group web site: available at: http://www.esrl.noaa.gov/gmd/hats/ combined/SF6.html (last access: 15 June 2013), 2013.

ISO 6142: Gas analysis - Preparation of calibration gas mixture Gravimetric method, 2001.

Lee, J., Lee, J., Moon, D., Kim, J. S., Wessel, R., Aoki, N., Kato, K., Guenther, F., Rhoderick, G., Konopelko, L. A., Han, Q., and Hall, B.: Final report on international comparison CCQMK68: Nitrous oxide in synthetic air, Metrologia, 48, 08004, doi:10.1088/0026-1394/48/1A/08004, 2011.

Min, D., Kang, N., Moon, D. M., Lee, J. B., Lee, D. S., and Kim, J. S.: Effect of variation in argon content of calibration gases on determination of atmospheric carbon dioxide, Talanta, 80, 422427, 2009.
Rigby, M., Mühle, J., Miller, B. R., Prinn, R. G., Krummel, P. B., Steele, L. P., Fraser, P. J., Salameh, P. K., Harth, C. M., Weiss, R. F., Greally, B. R., O’Doherty, S., Simmonds, P. G., Vollmer, M. K., Reimann, S., Kim, J., Kim, K.-R., Wang, H. J., Olivier, J. G. J., Dlugokencky, E. J., Dutton, G. S., Hall, B. D., and Elkins, J. W.: History of atmospheric $\mathrm{SF}_{6}$ from 1973 to 2008, Atmos. Chem. Phys., 10, 10305-10320, doi:10.5194/acp10-10305-2010, 2010.

van der Veen, A. M. H., Brinkmann, F. N. C., Amautovic, M., Besley, L., Hans-Joachim H., Esteban, T. L., Sega, M., Kato, K., Kim, J. S., Castorena, A. P., Rakowska, A., Milton, M. J. T., Guenther, F. R., Francey, R., and Dlugokencky, E.: International comparison CCQM-P41 greenhouse gases. 1. Measurement capability, Metrologia, 44, 08002, doi:10.1088/00261394/44/1 A/08002, 2007.

Wessel, R. M., van der Veen, A. M. H., Ziel, P. R., Steele, P., Langenfelds, R., van der Schoot, M., Smeulders, D., Besley, L., da Cunha, V. S., Zhou, Z., Qiao, H., Heine, H. J., Martin, B., Macé, T., Gupta, P. K., di Meane, E. A., Sega, M., Rolle, F., Maruyama, M., Kato, K., Matsumoto, N., Kim, J. S., Moon, D. M., Lee, J. B., Murillo, F. R., Nambo, C. R., Caballero, V. M. S., Salas, M. J. A., Castorena, A. P., Konopelko, L. A., Kustikov, Y. A., Kolobova, A. V., Pankratov, V. V., Efremova, O. V., Musil, S., Chromek, F., Valkova, M., Milton, M. J. T., Vargha, G., Guenther, F., Miller, W. R., Botha, A., Tshilongo, J., Mokgoro, I. S., and Leshabane, N.: International Comparison CCQM K52 - Carbon dioxide in Synthetic Air, Metrologia, 45, 08011, doi:10.1088/00261394/45/1 A/08011, 2008. 